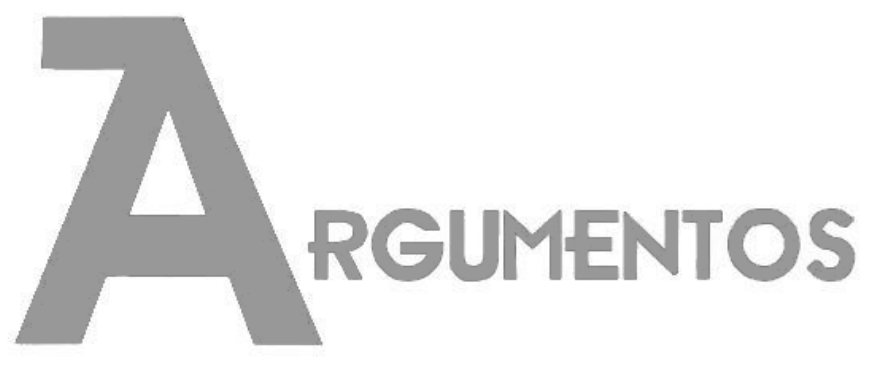

Vol. 17, n. 1, jan./jun. 2020 ISSN: 2527-2551 (online)

\title{
Conflitos ambientais no Norte De Minas Gerais: o 70 Encontro da Articulação dos Vazanteiros em Movimento ${ }^{1}$
}

\author{
Queite Marrone Soares da Silva² \\ Rumi Regina Kubo ${ }^{3}$
}

Recebido em: 08/10/2019

Aprovado em: 22/12/2019

Resumo: Este trabalho visa contribuir para a visibilização da Articulação dos Vazanteiros em Movimento, entendendo o seu processo de organização como instrumento de luta diante da sobreposição dos Parques Estaduais: Verde Grande (1998), Lagoa do Cajueiro (1998) e Mata Seca (2001), construídos como compensação aos impactos ambientais do Projeto de Fruticultura irrigada do Jaíba. Várias reivindicações foram apresentadas no 70 Encontro da Articulação dos Vazanteiros em Movimento, que ocorreu nos dias 28 e 29 de julho de 2017, reunindo comunidades que se reconhecem como tradicionais, entre elas, as comunidades de Pau Preto, Pau de Légua e Quilombo da Lapinha, localizadas nos municípios de Matias Cardoso e Manga, no Norte de Minas Gerais. A década de 50 marca o processo de modernização da agricultura no Brasil, nesta região, esteve pautada na agricultura/fruticultura irrigada, monoculturas de eucalipto, pecuária extensiva e monoculturas de algodão. Contexto de desenvolvimento que se propôs o Projeto Jaíba, entre os rios São Francisco e Verde Grande, abrangendo uma estrutura de $86.794,59$ hectares, sendo $65.879,98$ destinadas diretamente à

\footnotetext{
${ }^{1}$ A primeira versão deste trabalho foi apresentada no GT26 - Conflitos Socioambientais do 19o Congresso Brasileiro de Sociologia, 9 a 12 de julho de 2019, em Florianópolis - SC, na Universidade Federal de Santa Catarina. Posteriormente revisado para compor dossiê da Revista Argumentos.

2 Doutoranda em Desenvolvimento Rural pelo PGDR/UFRGS. Mestre em Desenvolvimento Social Pelo PPGDS/Unimontes. Bacharel em Ciências Sociais/Unimontes. Pesquisadora colaboradora no Núcleo Interdisciplinar de Investigação Socioambiental da Unimontes - NIISA/Unimontes, e no Núcleo de Estudos em Desenvolvimento Rural Sustentável e Mata Atlântica - DESMA/UFRGS. E-mail: queitemarroneppgdsunimontes@gmail.com. ORCID: https://orcid.org/0000-0003-0924-4434.

${ }^{3}$ Professora do Departamento de Ciências Econômicas e Relações Internacionais da Universidade Federal do Rio Grande do Sul. Possui graduação em Ciências Biológicas (1989) e em Artes Plásticas (2000), Mestrado em Botânica (1997) e doutorado em Antropologia Social (2006) pela Universidade Federal do Rio Grande do Sul. Atua junto ao Programa de Pós-graduação em Desenvolvimento Rural (PGDR/UFRGS) e integra os grupos Desma (Núcleo de Estudos em Desenvolvimento Rural Sustentável e Mata Atlântica), Navisual (Núcleo de Antropologia Visual) e Nesan (Núcleo de Estudos em Segurança Alimentar e Nutricional). E-mail: rumikubo2002@gmail.com. ORCID: https://orcid.org/0000-0002-2336-1402.
} 
irrigação. Este trabalho resulta das experiências junto ao Núcleo Interdisciplinar de Investigação Socioambiental da Universidade Estadual de Montes Claros, desdobrando-se no desenvolvimento da pesquisa de tese da autora.

Palavras-chave: Conflitos ambientais; Norte de Minas Gerais; Vazanteiros; Projeto Jaiba; Parques Estaduais.

\section{Conflictos ambientales en el Norte de Minas Gerais: la séptima reunión de La Articulación de Vazanteiros en Movimiento}

Resumen: Este trabajo tiene como objetivo contribuir a la visibilidad del Movimiento de Articulación Vazanteiros, entendiendo su proceso de organización como instrumento de lucha dada la superposición de los Parques Estatales: Verde Grande (1998), Lagoa do Cajueiro (1998) y Mata Seca (2001), construido como compensación por los impactos ambientales del Proyecto de fruta irrigada de Jaíba. Se presentaron varios reclamos en la séptimo Reunión de Vazanteiros en la Articulación del Movimiento, que tuvo lugar los días 28 y 29 de julio de 2017, que reunió a comunidades que se reconocen a sí mismas como tradicionales, entre ellas las comunidades de Pau Preto, Pau de Légua y Quilombo da Lapinha, ubicado en los municipios de Matias Cardoso y Manga, en el norte de Minas Gerais. La década de 1950 marca el proceso de modernización de la agricultura en Brasil, en esta región, se basó en la agricultura de riego / cultivo de frutas, monocultivos de eucalipto, monocultivos extensivos de ganado y algodón. Contexto de desarrollo propuesto por el Proyecto Jaíba, entre los ríos São Francisco y Verde Grande, que abarca una estructura de 86.794 .59 hectáreas, de las cuales 65.879 .98 están destinadas al riego directo. Este trabajo es el resultado de experiencias con el Centro Interdisciplinario de Investigación Socioambiental de la Universidad Estatal de Montes Claros, que se desarrolla en el desarrollo de la investigación de tesis del autor.

Palabras-clave: Conflictos ambientales; Norte de Minas Gerais; Vazanteiros; Proyecto Jaiba; Parques estatales.

\section{Environmental conflicts in North Minas Gerais: the sevent meeting of Articulation Vazanteiros in Movement}

Abstract: This work aims to contribute to the visibility of the Movement of Vazanteiros Articulation, understanding its process of organization as an instrument of struggle given the overlap of the State Parks: Verde Grande (1998), Lagoa do Cajueiro (1998) and Mata Seca (2001), built as compensation for the environmental impacts of the Jaíba Irrigated Fruit Project. Several claims were presented at the seventh Meeting of the Vazanteiros in Movement Articulation, which took place on July 28 and 29, 2017, bringing together communities that recognize themselves as traditional, among them the communities of Pau Preto, Pau de Légua and Quilombo da Lapinha, located in the municipalities of Matias Cardoso and Manga, in northern Minas Gerais. The 1950s mark the process of modernization of agriculture in Brazil, in this region, was based on irrigated agriculture / fruit growing, eucalyptus monocultures, extensive livestock and cotton monocultures. Development context proposed by the Jaíba Project, between the São Francisco and Verde Grande rivers, encompassing a structure of 86.794.59 hectares, of which 65.879 .98 are intended for direct irrigation. This work results from experiences with the Interdisciplinary Center for Socio-Environmental Research of the State University of Montes Claros, unfolding in the development of the author's thesis research.

Keywords: Environmental conflicts; North of Minas Gerais; Vazanteiros; Jaíba Project; State Parks. 
Dossiê | Conflitos ambientais no Norte De Minas Gerais: o 7º Encontro da Articulação dos Vazanteiros em Movimento (SILVA, Queite Marrone Soares da; KUBO, Rumi Regina)

\section{Introdução}

O presente trabalho tem como objetivo ampliar os espaços de visibilização da Articulação dos Vazanteiros em Movimento, e entender o seu processo de organização como instrumento de reivindicação e luta territorial, diante dos conflitos socioambientais que emergem em virtude da sobreposição dos Parques Estaduais: Verde Grande (1998), Lagoa do Cajueiro (1998) e Mata Seca (2001), construídos como medidas compensatórias aos impactos ambientais do Projeto de Fruticultura irrigada do Jaíba, no Norte de Minas Gerais. Este é conhecido regionalmente como Projeto Jaíba, considerado o maior projeto de irrigação em área contínua da América Latina.

De acordo com Poswar (2011) a identidade dos vazanteiros está relacionada ao uso que fazem das vazantes formadas a partir dos ciclos hídricos do Rio São Francisco, para se reproduzirem culturalmente, economicamente, simbolicamente e socialmente. Segundo Oliveira (2005) se refere a populações que residem em áreas inundáveis das margens e ilhas do rio São Francisco, possui modo de vida específico nos ambientes que compõe o seu território, realizando atividades de agricultura de vazante e sequeiro, pesca, criação de animal e extrativismo.

Esta proposta se concentra na análise das questões apresentadas no 70 Encontro da Articulação dos Vazanteiros em Movimento, que ocorreu nos dias 28 e 29 de julho de 2017, reunindo comunidades tradicionais, entre elas, as comunidades de Pau Preto, Pau de Légua e Quilombo da Lapinha, que se identificam como vazanteiras e constituem interlocutores deste trabalho. Estão localizadas nos municípios de Matias Cardoso e Manga, no Norte de Minas Gerais.

A década de 1950 marca o processo de modernização da agricultura no Brasil, no Norte de Minas Gerais esteve pautado na agricultura/fruticultura irrigada, monoculturas de eucalipto, pecuária extensiva e monoculturas de algodão. Segundo Dayrell (2000) a "chegada das firmas", expressão regional utilizada para se referir aos empreendimentos capitalistas, marca o início deste processo que se intensifica devido à racionalidade produtiva baseada na economia capitalista, desconsiderando as especificidades locais.

Nesta lógica de desenvolvimento, sobretudo, com a atuação da 
Dossiê | Conflitos ambientais no Norte De Minas Gerais: o 7ํㅡㄹ Encontro da Articulação dos Vazanteiros em Movimento (SILVA, Queite Marrone Soares da; KUBO, Rumi Regina)

Superintendência do Desenvolvimento do Nordeste (SUDENE) e da Fundação Rural Mineira (RURALMINAS), criou-se o Projeto Jaíba entre os rios São Francisco e Verde Grande, por meio de uma área de 86.794,59 hectares, sendo 65.879,98 hectares destinadas diretamente à irrigação. Os impactos ambientais decorrentes deste Projeto justificam a obrigatoriedade do cumprimento de medidas compensatórias, sob a forma de Parques Estaduais, Áreas de Proteções Ambientais e Reservas Biológicas, que correspondem a uma área de $90.078,80$ hectares.

A instalação das unidades de conservação na modalidade de proteção integral provocou um intenso conflito com as comunidades locais, sobretudo, a partir da restrição e criminalização de práticas produtivas tradicionais. Este processo reforçou a expropriação fundiária, ou o chamado "encurralamento" fundiário 4 das terras-firmes, confinando-os às ilhas e barrancos do rio São Francisco, bem como a migração para as cidades próximas, num contexto de construção de inúmeras estratégias de resistência para a reprodução social dos grupos.

O encurralamento é uma expressão histórica e nativa utilizada na região, para situar a sobreposição de territórios ao longo da bacia do alto e médio São Francisco, através da ocupação por bandeirantes e grandes fazendas. O termo assume um papel político no processo de denúncia e de resistência dos grupos sociais, que reivindicam o reconhecimento das diferenças culturais.

Alguns pesquisadores asseguram que a inserção de empreendimentos desenvolvimentistas, e a modernização da agricultura no Norte de Minas Gerais foram processos que provocaram a invisibilização de várias comunidades e grupos sociais, cuja reprodução social, cultural e econômica depende da biodiversidade. Estas afirmativas podem ser constatadas em Costa (2011), Dayrell (2000), Feitosa e Barbosa (2006), França; Barbosa; Soares (2006), Gonçalves (2000), entre outros.

Neste cenário se configuram situações de conflitos, envolvendo lógicas

\footnotetext{
${ }^{4} \mathrm{O}$ termo encurralamento é uma analogia a perda de espaço físico do gado por meio dos currais, sendo apropriado regionalmente pelas comunidades tradicionais do norte de Minas Gerais em suas reivindicações, para denunciar a perda de direitos e espaços físicos e simbólicos, diante das ações de empreendimentos com lógicas e percepções diferenciadas. Para os Vazanteiros, o encurralamento ocorre por meio da criação de Unidades de Conservação como medidas compensatórias ao Projeto Jaíba, que sobrepõem seus territórios tradicionais reivindicados, limitando de forma significativa suas formas de produção.
} 
Dossiê | Conflitos ambientais no Norte De Minas Gerais: o 7º Encontro da Articulação dos Vazanteiros em Movimento (SILVA, Queite Marrone Soares da; KUBO, Rumi Regina)

distintas de significação e manejo dos recursos naturais. No caso em questão, relacionam-se principalmente com a criação de unidades de conservação nos territórios tradicionais, num processo que em seu regramento desconsidera as especificidades das comunidades locais e provoca a descaracterização de suas práticas socioprodutivas. Por meio da Articulação dos Vazanteiros em Movimento reivindicam os territórios e o reconhecimento de suas territorialidades.

Os dados para a presente análise foram obtidos através da participação como pesquisadora no Projeto "Dinâmicas Socioambientais na Bacia Média do Rio São Francisco Mineiro: identificação e caracterização de terras tradicionalmente ocupadas por povos e comunidades tradicionais", em parceria com o Projeto "Tropi Dry IV"/Universidade Alberta do Canadá, ambos inseridos nas propostas do Núcleo Interdisciplinar de Investigação Socioambiental da Universidade Estadual de Montes Claros (NIISA/Unimontes). Utilizamos referências bibliográficas de pesquisas regionais e dados coletados em campo, por meio das entrevistas, diálogos, registros visuais e observações durante este evento.

\section{Processos importantes: uma breve contextualização do Norte de Minas Gerais}

O sertão Norte Mineiro foi tratado como culturalmente fora dos centros dinâmicos do mundo moderno, segundo Costa (2011) eram "terras de ninguém" ou "terras que ninguém queria". Por outro lado, constituiu-se em um espaço territorial de construção de liberdade, autonomia e afirmação, "essas gentes passaram a ser classificadas como 'pequenos produtores', 'sitiantes', 'posseiros', 'agregados' e atualmente 'agricultores familiares'”. (COSTA, 2011, p. 54-55).

Ribeiro (2000) afirma que o termo sertão vai ao encontro com a idéia de que estava fora dos centros dinâmicos do mundo moderno, espacialmente periféricos, representava o "atraso" frente ao "progresso", tratado de forma depreciativa. Todo o interior do Brasil era um imenso sertão, sendo Minas Gerais no início da descoberta do ouro conhecida como "Sertão de Cataguases".

Após o processo de colonização, o estado de Minas Gerais deixa de ser reconhecido como Sertão dos Cataguases. Contudo, de um lado se encontra a área mineradora até a Comarca de Sabará, e de outro o sertão mineiro que se destaca pela 
Dossiê | Conflitos ambientais no Norte De Minas Gerais: o 7º Encontro da Articulação dos Vazanteiros em Movimento (SILVA, Queite Marrone Soares da; KUBO, Rumi Regina)

pecuária e agricultura que eram desenvolvidas ao redor das fazendas, além da agricultura de auto-abastecimento destinada aos camponeses. (FRANÇA; BARBOSA; SOARES, 2006).

No processo de colonização, a metrópole portuguesa administrava as minas de ouro e se interessava pelo controle territorial dos campos gerais. Esta denominação era dada pela referência às terras onde o modo de apropriação dos recursos naturais disponíveis era comum, e representavam a condição de garantia da subsistência. Segundo Gonçalves (2000, p. 24) "Campos Gerais indicam um modo de uso, um modo de apropriação comum, geral das terras. Indica que eles não são particulares, privados. São Gerais, são comuns."

De acordo com França; Barbosa; Soares (2006) a visão que foi construída sobre o cerrado e suas populações, a partir dos escritos dos europeus no século XIX está relacionada com essas transformações ocorridas na região. Assim, foram tratadas de forma depreciativa, com a ótica de que a inserção dos projetos desenvolvimentistas traria soluções. Estas populações não foram reconhecidas como autônomas em sua produção, cujos modos de vida se diferenciam das ações do capital agroindustrial, e portanto, pode-se considerar que foram subalternizadas e invisibilizadas nestes processos.

Os espaços de uso comunal (chapadas) foram tratados como lugares improdutivos na perspectiva da lógica capitalista. Deste modo, a criação de projetos desenvolvimentistas ocorridos principalmente nas décadas de 1960 e 1970 contribuiu para o empobrecimento da população regional, agravando as condições socioeconômicas, comprometendo os seus recursos naturais e sua sustentabilidade, diante de um processo compreendido como excludente. (GONÇALVES, 2000).

A execução de projetos desenvolvimentistas ocorridos com a criação da SUDENE e com inúmeros programas de investimentos marca o processo de modernização da agricultura no Norte de Minas Gerais, pautado na agricultura irrigada (especialmente fruticultura), monoculturas de eucalipto e algodão, e pecuária extensiva. Sob esta lógica ocorre a implantação do Projeto de Irrigação Jaíba, entre os Rios São Francisco e Verde Grande, na década de 1950, com a previsão de quatro etapas de implantação, tendo o apoio do Governo federal e do Governo do estado de Minas Gerais. 
Dossiê | Conflitos ambientais no Norte De Minas Gerais: o 7ํㅡㄹ Encontro da Articulação dos Vazanteiros em Movimento (SILVA, Queite Marrone Soares da; KUBO, Rumi Regina)

As potencialidades agrícolas da região denominada de Mata do Jaíba foram analisadas com alguma profundidade na década de 1960, sendo identificada uma área de cerca de 230.000 hectares para aproveitamento agropecuário, segundo estudos apresentados em 1965, reunidos sob o título de "Reconhecimento dos Recursos Hidráulicos e de Solos da Bacia do Rio São Francisco".

Com o propósito de estabelecer um projeto de desenvolvimento e de colonização da região noroeste do estado mineiro, em 1966 o Governo do Estado de Minas Gerais lança o Plano de Desenvolvimento Integrado da Região Noroeste (PLANOROESTE), criando para administrá-lo a RURALMINAS. Desta forma, a Mata do Jaíba foi escolhida para transformar-se no mais importante pólo agroindustrial da região, dentro dos $115.000 \mathrm{Km}^{2}$ abrangidos pelo PLANOROESTE.

O final da década de 1980 é marcado pelo início da operação do Projeto, com o assentamento das primeiras famílias de irrigantes, e também com a incorporação da iniciativa privada ao Projeto, através da criação do Distrito de Irrigação de Jaíba (DIJ), entidade privada sem fins lucrativos, gerida pelos irrigantes e que tem por finalidade administrar toda a estrutura construída.

A infraestrutura hidráulica principal do Projeto Jaíba com capacidade para atender a todas as suas etapas foi concluída, totalizando uma área de $86.794,59$ hectares. A I Etapa do Projeto abrange uma área total de 32.959,33 hectares com 2.153 lotes. A II Etapa sob iniciativa do Governo de Minas Gerais, cuja implantação teve início no primeiro trimestre de 1999, possui uma área de 22.606,26 hectares com 684 lotes. Percebe-se uma concentração fundiária maior na etapa II em relação à primeira etapa do projeto. Já existe uma estrutura que prevê a implementação das etapas III e IV, com a área respectivamente de 17.400,00 hectares e 13.829,00 hectares.

Segundo Santos (2013) no Projeto Jaíba não há espaço de produção para subsistência, a proposta é a transformação numa lógica empreendedora. Estas dinâmicas configuram disputas entre diferentes grupos. Por um lado, segmentos que defendem a concepção de ganho para a região, a partir da premissa de desenvolvimento compreendido pelo crescimento econômico. Por outro lado, estas questões reposicionam outros grupos que ocupam/ocupavam estes espaços, e que vivenciam processos de desapropriação a partir das compensações ambientais deste grande projeto de irrigação. 
Dossiê | Conflitos ambientais no Norte De Minas Gerais: o 7ํㅡㄹ Encontro da Articulação dos Vazanteiros em Movimento (SILVA, Queite Marrone Soares da; KUBO, Rumi Regina)

Intensifica-se com isso os processos de luta por terra no Norte de Minas Gerais, produzindo um cenário de resistência diante da expulsão das famílias pelos empreendimentos que se estabeleciam na região, num contexto que possibilitou a origem dos primeiros assentamentos rurais. Estas questões exerceram forte influência na vida das comunidades tradicionais, que se posicionam contra a expropriação das empresas de reflorestamento e fazendeiros, cujo propósito era ampliar os projetos de pecuária extensiva. (FEITOSA E BARBOSA, 2006).

Para estas comunidades a modernização agrícola interferiu nas condições de vida, nos sistemas de produção e no domínio territorial, significando um violento processo de ruptura com a expulsão de famílias das terras que foram tradicionalmente ocupadas por seus ancestrais. (COSTA, 2011).

As "terras tradicionalmente ocupadas" segundo Almeida (2011) estão relacionadas às formas diversas de existência coletiva de diferentes grupos sociais, e as relações estabelecidas com os recursos naturais. Estas formações históricas diferenciadas foram inseridas na Constituição Federal de 1988, no entanto são muitas as tensões existentes no processo de reconhecimento jurídico-formal, uma vez que esta inserção não ocorreu por meio do entendimento de todas as reivindicações dos Movimentos Sociais. Deste modo, não resultou em resoluções de conflitos para o reconhecimento de direitos étnicos, territorialidade, identidade, organização social e modos de vida.

A Constituição Federal de 1988 determinou garantias aos grupos sociais que contribuíram historicamente para a formação da sociedade brasileira. Conforme afirma Costa (2015) todos os demais indivíduos passam a se tornar sujeitos de direitos e a reivindicar a (des)invisibilização, contrapondo ao sujeito iluminista de construção da modernidade (homem, branco e proprietário).

No entanto, a Constituição Federal não garantiu efetivamente na prática tais direitos. Esta situação resultou na emergência de processos sociais de lutas e resistências de grupos rurais e urbanos, pelo reconhecimento de direitos relativos à diferença e identidade étnica, por meio de uma construção política de acionamento da identidade para reivindicações territoriais.

\section{Comunidades Tradicionais Vazanteiras e as Unidades de Conservação}


Dossiê | Conflitos ambientais no Norte De Minas Gerais: o 7ํㅡㄹ Encontro da Articulação dos Vazanteiros em Movimento (SILVA, Queite Marrone Soares da; KUBO, Rumi Regina)

Os conflitos se intensificam na região com a criação de unidades de conservação como medidas compensatórias destes grandes empreendimentos, ao longo da baixada média do Rio São Francisco, nos municípios de Matias Cardoso e Manga. Nesta perspectiva que surge a articulação dos Vazanteiros em Movimento, contestando os impactos gerados às suas formas tradicionais de produção e reprodução, mediante a sobreposição dos parques estaduais: Verde Grande (1998), Lagoa do Cajueiro (1998) e Mata Seca (2001), condicionantes para a implementação da etapa II do Projeto Jaíba.

A articulação se constitui em um importante movimento social de reivindicação territorial no campo ambiental, reunindo várias comunidades tradicionais que contrapõem distintos projetos desenvolvimentistas e defendem o rio São Francisco. De acordo com Anaya (2012) as reivindicações territoriais das comunidades vazanteiras de Pau Preto, Pau de Légua e Quilombo da Lapinha por meio da articulação dos "Encurralados Pelos Parques" a "Vazanteiros em Movimento", se originou com o processo de encurralamento e expropriação territorial conseqüente à criação destas Unidades de Proteção Integral (UPI's), num processo que desconsidera as singularidades dos modos de vida das comunidades tradicionais locais.

De acordo com Little (2002) existe uma diversidade sociocultural no Brasil que corresponde a vários grupos humanos entendidos por meio de diversas categorias e adjetivos, sejam elas "populações", "comunidades, "povos", "sociedades" e "culturas", que podem ser "tradicionais", "rurais" ou "locais". A diversidade dos grupos que as englobam tornam suas combinações complexas. O conceito envolve um conjunto de grupos sociais que historicamente mostram formas sustentáveis de manejo dos recursos naturais.

Trazendo para o debate a noção do direito e de sujeitos de direitos, Little (2002) faz a opção política pelo termo "povos tradicionais", afirmando a imensa diversidade sociocultural e fundiária no Brasil. Esta escolha categórica representa um instrumento estratégico nas lutas por justiça social dos povos, através do reconhecimento da legitimidade de seus regimes de propriedade comum, e das leis consuetudinárias que os fundamentam. Deste modo, os inserem nos debates sobre os direitos dos povos, através da dimensão empírica e política em favor dos seus respectivos territórios, frente 
Dossiê | Conflitos ambientais no Norte De Minas Gerais: o 7ํㅡㄹ Encontro da Articulação dos Vazanteiros em Movimento (SILVA, Queite Marrone Soares da; KUBO, Rumi Regina)

à usurpação por grupos sociais vinculados ao Estado-nação ou pelo próprio Estado.

Neste sentido, trata-se de uma categoria construída politicamente, com o propósito de legitimar direitos. Conforme o Inciso I do Art. 3으 do Decreto № 6.040, de 7 de Fevereiro de 2007, compreende-se:

Povos e Comunidades Tradicionais: grupos culturalmente diferenciados e que se reconhecem como tais, que possuem formas próprias de organização social, que ocupam e usam territórios e recursos naturais como condição para sua reprodução cultural, social, religiosa, ancestral e econômica, utilizando conhecimentos, inovações e práticas gerados e transmitidos pela tradição; [.. ${ }^{5}$

Ao instituir a Política Nacional de Desenvolvimento Sustentável dos Povos e Comunidades Tradicionais, o Art.3으 do referido decreto ressalta que os Territórios Tradicionais se referem aos espaços necessários a reprodução cultural, social e econômica das comunidades em constante equilíbrio com os recursos naturais.

A identificação dos vazanteiros está relacionada ao uso que fazem das vazantes formadas a partir dos ciclos do rio São Francisco, para se reproduzirem culturalmente, economicamente, simbolicamente e socialmente. (POSWAR, 2011).

Vazanteiros são as populações residentes nas áreas inundáveis das margens e ilhas do rio São Francisco que se caracterizam por um modo de vida específico, construído a partir do manejo dos ecossistemas sanfranciscanos, combinando nos diversos ambientes que constituem seu território atividades de agricultura de vazante e sequeiro, com a pesca, a criação animal e o extrativismo. (OLIVEIRA, 2005, p. 10).

Constituem importantes redes sociais, ou seja, as comunidades tradicionais não estão isoladas ou desconectadas, são distinguidas pelas singularidades que possuem e que as unem em comunidade, se reconhecendo como tal. De acordo com Brandão (2012, p. 371) “são comunidades tradicionais aquelas que 'ali estavam' quando

5 Brasil. Decreto № 6.040, de 7 de Fevereiro de 2007. Disponível em: http://www.planalto.gov.br/ccivil 03/ ato2007-2010/2007/decreto/d6040.htm. Acesso em 10 de Agosto de 2018. 
Dossiê | Conflitos ambientais no Norte De Minas Gerais: o 7º Encontro da Articulação dos Vazanteiros em Movimento (SILVA, Queite Marrone Soares da; KUBO, Rumi Regina)

outros grupos humanos, populares ou não, 'ali chegaram' e se estabeleceram."

As comunidades tradicionais ocupam territórios, socializam a natureza, se relacionam com outros grupos, são agentes de sustentabilidade, e não estão fora da economia central. Estas comunidades são caracterizadas pela autonomia; memórias de lutas passadas de resistência; experiência de vida em territórios cercados e ameaçados; transformação da natureza; e historias de lutas e resistências atuais. (BRANDÃO, 2012).

Neste sentido, a efetivação das unidades de proteção integral no Norte de Minas Gerais provocou a restrição de práticas tradicionais destas comunidades, reforçando o processo de "encurralamento" e de restrição das comunidades de Pau Preto, Pau de Légua e Quilombo da Lapinha, que junto a outras comunidades reivindicam o seu território e as condições necessárias para se (re) produzirem tradicionalmente.

Foi destinada uma área total de $90.078,80$ hectares correspondente as categorias de Proteção Ambiental, Parque Estadual, Corredor Ecológico, Reserva Biológica e Reserva Legal, distribuídas da seguinte forma: Parque Estadual do Rio Verde Grande (25.443,20 ha), Parque Estadual da Lagoa do Cajueiro (20.728,00 ha), Parque Estadual da Mata Seca (10.155,90 ha), Área de Proteção Ambiental Lagedão (11.223,00 ha), Área de Proteção Ambiental Sabonetal (em execução conforme informação do site do projeto), Reserva Biológica da Serra Azul (7.803,90 ha), Reserva Legal (8.182,00 ha), Reserva Biológica (6.304,60 ha) e Corredor Ecológico (238,20 ha). ${ }^{6}$

Diegues (2001) ao analisar o contexto de áreas naturais protegidas em contraste com os meios tecnológicos devastadores da natureza, afirma que permanecem os mitos sobre sua conservação, originários de países industrializados e adotados por muitos ambientalistas que defendem as áreas intocadas e desabitadas, desconsiderando o ser humano nesta interação. Esta idéia confronta-se com a percepção que as comunidades tradicionais possuem em relação ao mundo natural. 0 autor faz uma crítica à exportação do modelo de parques norte americano, cujas áreas naturais protegidas se constituem numa política conservacionista que partem da visão do homem como destruidor da natureza.

\footnotetext{
${ }^{6}$ Ficha Fundiária do Projeto Jaiba. Disponível em: http://www.projetojaiba.com.br/index.php/paginas/3.
} 
Dossiê | Conflitos ambientais no Norte De Minas Gerais: o 7ํㅡㄹ Encontro da Articulação dos Vazanteiros em Movimento (SILVA, Queite Marrone Soares da; KUBO, Rumi Regina)

No contexto dos países subtropicais se tem um demasiado conflito, uma vez que as florestas já eram habitadas por indígenas e grupos tradicionais com formas de apropriação comunal dos recursos naturais. A visão da natureza intocada cria conflitos que acarretam na perda do território ancestral destas comunidades, conforme a legislação referente às unidades de conservação restritivas. Ao longo dos anos os conhecimentos deste mundo natural os capacitaram a criar sistemas de manejo da fauna e da flora, protegendo, conservando e contribuindo para a diversidade biológica. Após o regime militar no Brasil, onde se criou um número significativo destas áreas protegidas, as comunidades tradicionais recriam estratégias de resistência, propondo novos modelos de se entender e construir as áreas protegidas. (DIEGUES, 2001).

Segundo Acselrad (2004) os conflitos se estabelecem a partir do embate entre os diferentes modos de apropriação, significação e uso dos recursos naturais. Para o autor, a apropriação do mundo material não ocorre somente para a superação de carências e restrições materiais, mas também consistem em projetar diferentes significados, através das estruturas desiguais de poder, distribuição e acesso. Os conflitos "podem configurar-se tanto através de uma luta direta no espaço de distribuição do poder sobre a base material, como uma luta simbólica em torno às categorias de legitimação das práticas." (ACSELRAD, 2004, p. 24).

Durante o processo de distribuição e acesso aos recursos naturais existem diferentes formas de apropriação, entre elas, a simbólica e a material, que acontece entre sujeitos socialmente desiguais. Os conflitos ocorrem quando pelo menos um dos grupos sociais com modo de vida diferenciado, tem a continuidade de suas formas de apropriação ameaçadas pelas práticas de outros grupos. (ACSELRAD, 2004). Deste modo, as necessidades ilimitadas dos humanos e as suas diferentes formas de percepção, acesso e apropriação traduzem crises sociais. Neste contexto de disputas por recursos simbólicos e materiais que se instituem os conflitos, expressão das tensões no processo de reprodução de modelos de desenvolvimento.

A respeito da conduta territorial e dos processos sociais, históricos e políticos, Little (2002, p.3) define "[...] a territorialidade como o esforço coletivo de um grupo social para ocupar, usar, controlar e se identificar com uma parcela específica de seu ambiente biofísico, convertendo-a assim em seu 'território'." O manejo dos recursos naturais ocorre de forma comunitária, através de uma rede de relações de 
Dossiê | Conflitos ambientais no Norte De Minas Gerais: o 7º Encontro da Articulação dos Vazanteiros em Movimento (SILVA, Queite Marrone Soares da; KUBO, Rumi Regina)

reciprocidade, com práticas de adaptação pouco agressivas aos ecossistemas, tendo em vista os importantes vínculos sociais, culturais e simbólicos.

O contexto da expansão da fronteira agrícola, sobretudo, nas áreas nativas ou manejadas por meio de práticas de 'pouco impacto' tem implicações econômicas, sociais e ecológicas, que representam um grande desafio para as comunidades tradicionais locais, tendo em vista a relação que estas estabelecem com a vegetação nativa da região para a reprodução de suas singularidades.

As comunidades tradicionais locais respondem a estas questões com a organização e mobilização política, visibilizando cada vez mais os seus discursos e reivindicações, no âmbito regional, estadual, nacional e internacional, por meio das redes sociais que são possibilitadas pelos ambientes virtuais, e pela atuação constante nos eventos dos movimentos sociais que compõe sua rede sócio-política. Neste processo, as diversas edições dos Colóquios Internacionais de Povos e Comunidades Tradicionais, de iniciativa do Programa de Pós Graduação em Desenvolvimento Social da Unimontes, em parceria com a Universidade de Kassel (Alemanha), têm buscado oportunizar um espaço de articulação dos diversos atores sociais, organizações e instituições que debatem as dinâmicas territoriais e os processos de disputas.

Deste modo, a articulação dos Vazanteiros em Movimento significa um importante instrumento de luta contínua dos Vazanteiros e de todas as demais comunidades tradicionais que foram se inserindo ao movimento, sobretudo pelo contexto de transformações que afetam seus territórios. Além disso, tem se ampliado cada vez mais as parcerias estabelecidas com outros movimentos de Povos e Comunidades Tradicionais, para além das alianças já estabelecidas com a Comissão da Pastoral da Terra, Centro de Agricultura Alternativa do Norte de Minas Gerais, Liga dos camponeses e Grupos de pesquisas das Universidades, entre elas a Unimontes e a UFMG.

\section{As reivindicações do 70 Encontro da Articulação dos Vazanteiros em Movimento}

As primeiras iniciativas governamentais de ocupação planejada da área do Jaíba nas décadas de 1960 a 1970, e as políticas direcionadas a modernização da agricultura acentuaram os conflitos territoriais na região, processo em que se destacam 
Dossiê | Conflitos ambientais no Norte De Minas Gerais: o 7ํㅡㄹ Encontro da Articulação dos Vazanteiros em Movimento (SILVA, Queite Marrone Soares da; KUBO, Rumi Regina)

a atuação da Sudene e Ruralminas, no subsídio aos projetos e na regularização fundiária, como destacado anteriormente.

O contexto de políticas ambientais implementadas na região, e a transformação da dinâmica territorial dos vazanteiros no final dos anos 1990 e meados dos anos 2000 provoca a necessidade da unificação da luta pela reapropriação dos territórios ancestrais. Deste modo, surge em 2005 o "Movimento dos Encurralados pelos Parques" após vários encontros de articulação das comunidades e várias ações coletivas no campo ambiental. Posteriormente este movimento foi ressignificado para "Vazanteiros em Movimento", com a inserção de outros grupos sociais contestando os impactos dos diferentes projetos desenvolvimentistas na região.

Acselrad (2010, p. 109) destaca a existência de uma distribuição desigual dos benefícios e danos ambientais, que impõe os custos ambientais do desenvolvimento para os mais despossuídos, de modo que "o ambiente de certos sujeitos sociais prevaleça sobre o de outros, fazendo surgir o que se veio denominar de 'conflitos ambientais'", ou seja, os riscos e impactos ambientais tendem a atingir os mais vulneráveis.

O entendimento da necessidade de conservação integral que resulta na efetivação das unidades trouxe conseqüências às praticas tradicionais dos vazanteiros, por meio da criminalização e restrição de suas práticas, sobretudo, pela fiscalização dos agentes ambientais do Instituto Estadual de Florestas (IEF), especialmente no que se refere às práticas extrativistas, de caça, plantio e pesca que fazem parte do modo tradicional de vida do vazanteiro.

Neste contexto, se desdobram as estratégias cotidianas de convivência, resistência e reprodução, através da intensificação da prática da agricultura na vazante. Áreas que não eram habitadas se transformaram em locais de trabalho e de moradia, como as ilhas e beira-rio, com o propósito de ainda manterem alguma parte dos seus territórios. Em outros casos, Anaya (2014) afirma que muitas famílias migraram para as regiões periféricas das cidades de Manga e Matias Cardoso, criando um sistema próprio, precário e temporário.

O processo de politização e ambientalização desses grupos atingidos pelos parques estaduais ocorrem a partir da constituição de uma rede social de apoio, reconhecida como Fórum de Desenvolvimento Regional: Sindicatos dos Trabalhadores 
Dossiê | Conflitos ambientais no Norte De Minas Gerais: o 7ํㅡㄹ Encontro da Articulação dos Vazanteiros em Movimento (SILVA, Queite Marrone Soares da; KUBO, Rumi Regina)

Rurais (STR), Centro de Agricultura Alternativa (CAA), Comissão Pastoral da Terra (CPT), Movimento Contra o Deserto Verde, Movimento dos Atingidos por Barragens (MAB), Movimento dos Sem Terra (MST), Liga Camponesa, Universidades, entre outros, que problematizam as políticas de modernização do campo. Essa rede possibilitou a formação de lideranças comunitárias, a articulação de suas lutas territoriais no campo agrário e ambiental, o compartilhamento de uma agenda coletiva e a visibilização dessas coletividades. (ANAYA 2012).

A ambientalização é entendida a partir da noção que Acselrad (2010) aponta sobre os discursos e justificativas ambientais sendo adotados por distintos grupos sociais, para legitimar práticas institucionais, políticas e científicas. Nestes processos ocorrem às disputas por legitimidade, no intuito de caracterizar as diferentes práticas como ambientalmente benignas ou danosas, ocorrendo a ambientalização de discursos de diferentes atores sociais, que contestam formas desiguais de apropriação e distribuição dos recursos naturais. O processo de articulação dos vazanteiros alia o reconhecimento cultural e o acionamento identitário, na afirmação das formas singulares de organização social e convívio com o meio, na constituição dos seus modos de vida e territorialidade.

Neste contexto, a articulação dos Vazanteiros tem sido um importante instrumento nas reivindicações territoriais de distintos grupos sociais, que se organizam para manifestar os impactos destes processos na restrição de suas práticas tradicionais. Segue uma breve sistematização cronológica dos eventos da articulação, a partir do registro de Anaya (2014). O I Encontro Interestadual de Homens e Mulheres Vazanteiros do São Francisco foi realizado na Ilha da Ingazeira em 2005 entre os municípios de Manga (MG) e Carinhanha (BA), resultando em uma Carta Manifesto à sociedade em geral, para visibilizar o modo de vida vazanteiro. O II encontro das Comunidades Vazanteiras foi realizado em 2007 na Serra do Ramalho (BA), de modo que a Reserva Extrativista (RESEX) observada no texto do SNUC (2000) se apresenta como uma estratégia política para a permanência nos territórios, surgindo uma proposta de reconversão de parte do Parque Estadual Verde Grande em uma Unidade de Uso Sutentável, reunindo áreas de conservação e manejo agro-extrativista, com técnicas de recuperação de sistemas agroflorestais. (ANAYA, 2014).

Em setembro de 2008 realizou-se o III grande evento, o "Encontro da Ilha da 
Dossiê | Conflitos ambientais no Norte De Minas Gerais: o 7º Encontro da Articulação dos Vazanteiros em Movimento (SILVA, Queite Marrone Soares da; KUBO, Rumi Regina)

Ressaca" no Quilombo da Lapinha (MG), denominado Seminário Vazanteiros do São Francisco: entre os labirintos das leis ambientais e os direitos territoriais das populações tradicionais, que resultou na produção do "mapa do encurralamento" e visibilizou a situação de várias comunidades. O IV Encontro dos Vazanteiros na Ilha de Pau de Légua (MG) ocorreu em abril de 2009 com objetivo de fortalecer a articulação entre os grupos e analisar as relações de tensionamento, como aplicação de multas, apreensão de material de trabalho, entre outras ações. O "V Encontro" ocorreu nos dias 16 e 17 de setembro de 2010 na Ilha do Jenipapo, no município de Itacarambi (MG). Foi denominado de Vazanteiros em Movimento: povos das águas e terras crescentes, com o propósito de discutir as propostas sobre regularização dos territórios vazanteiros, e a revitalização socioambiental do Vale do São Francisco. (ANAYA, 2014).

Ao longo dos anos, os eventos foram se fortalecendo com a ampliação das redes de parcerias e mobilizações. Para este trabalho não foi possível mencionar o VI encontro, tendo em vista que não encontramos registros do mesmo. O VII Encontro da Articulação dos Vazanteiros em Movimento, foco deste trabalho, ocorreu no dia 28 e 29 de julho de 2017 no Quilombo da Lapinha, em Matias Cardoso (MG), juntamente com a Articulação Rosalino de povos e Comunidades Tradicionais ${ }^{7}$. Houve a participação de aproximadamente cem pessoas, entre elas, lideranças das comunidades tradicionais da região, pesquisadores do Núcleo de Investigação Socioambiental da Universidade Estadual de Montes Claros (NIISA/UNIMONTES), Centro de Agricultura Alternativa do Norte de Minas Gerais (CAA-NM), pesquisadores da Rede Tropi Dry, Liga Camponesa e Comissão Pastoral da Terra (CPT).

O encontro foi dividido em dois momentos importantes. Primeiramente foi feita uma retrospectiva dos encontros dos vazanteiros ao longo dos anos, por meio de uma dinâmica de trabalho em grupo sobre os desafios vivenciados e as conquistas obtidas. No segundo momento, houve a sistematização e a reflexão sobre o processo de construção política do movimento e suas reivindicações territoriais.

\footnotetext{
${ }^{7}$ A articulação Rosalino foi formalizada durante as Festas de Agosto, do ano de 2010, em um evento no Solar dos Sertões, localizado em Montes Claros - MG, com o objetivo de unificar as lutas sociais dos povos e comunidades tradicionais do Norte de Minas Gerais. O nome consiste em uma homenagem ao cacique Rosalino Gomes de Oliveira, assassinado em 1987, em São João das Missões, no Norte de Minas Gerais.
} 
Dossiê | Conflitos ambientais no Norte De Minas Gerais: o 7ํㅡㄹ Encontro da Articulação dos Vazanteiros em Movimento (SILVA, Queite Marrone Soares da; KUBO, Rumi Regina)

Figura 01. Comunidades tradicionais no 70 Encontro da Articulação dos Vazanteiros em Movimento

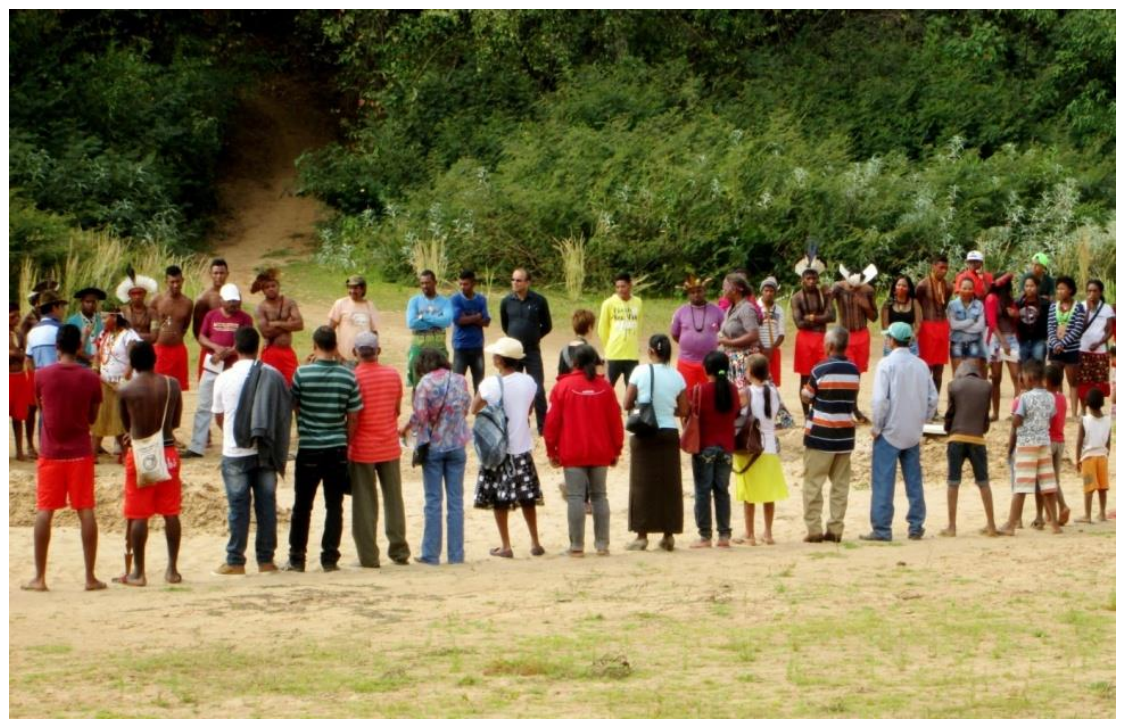

FONTE: SILVA, Queite Marrone Soares da. O 70 Encontro da Articulação dos Vazanteiros em Movimento, 2017.

As lideranças comunitárias debateram criticamente sobre o modelo de desenvolvimento implementado na região, além disso, reivindicaram a retomada dos seus territórios e a conservação do rio São Francisco, elemento fundamental para seus modos de vida. Outras questões foram citadas, como a relevância da unificação das lutas dos povos e das comunidades tradicionais, a demarcação dos territórios, e a ampliação das políticas públicas voltadas aos povos e comunidades tradicionais, reafirmando a importância da articulação para a permanente formação dos grupos.

Deste modo, cinco grupos de trabalhos foram organizados para a reflexão das conquistas e dificuldades que envolvem as reivindicações das comunidades tradicionais. A sistematização abaixo pontua brevemente algumas das questões que foram enfatizadas durante a plenária. 


\begin{tabular}{|l|l|}
\hline \multicolumn{1}{|c|}{ AVANÇOS E CONQUISTAS } & \multicolumn{1}{|c|}{ PRINCIPAIS DIFICULDADES } \\
\hline $\begin{array}{l}\text { Trabalho antropológico feito no território; } \\
\text { medição e cadastramento das famílias pela } \\
\text { Secretaria do Patrimônio da União (SPU). }\end{array}$ & $\begin{array}{l}\text { Impasses nas negociações; impactos } \\
\text { ambientais, e criminalização das práticas } \\
\text { tradicionais. }\end{array}$ \\
\hline $\begin{array}{l}\text { Envolvimento da juventude nos processos } \\
\text { de luta pelo território; parcerias com o CAA } \\
\text { e CPT; criação da Articulação Rosalino que } \\
\text { possibilitou intercâmbios. }\end{array}$ & $\begin{array}{l}\text { Dificuldades no diálogo com o governo } \\
\text { estadual; atuação rigorosa de instituições } \\
\text { no processo de fiscalização; criminalização } \\
\text { das praticas de manejo das comunidades. }\end{array}$ \\
\hline $\begin{array}{l}\text { Avanço com a aprovação do Laudo } \\
\text { Antropológico; publicações de trabalhos e } \\
\text { jornais; demarcação de territórios; } \\
\text { instalação de caixas de água e energia } \\
\text { elétrica; conquista da derrubada de } \\
\text { liminares, através dos advogados do CAA e } \\
\text { da parceria com o NIISA/Unimontes. }\end{array}$ & $\begin{array}{l}\text { Sobreposição dos Parques localizados } \\
\text { dentro do território; dificuldade dos } \\
\text { moradores em acessar a Emater em } \\
\text { Matias Cardoso e obter a DAP; } \\
\text { Saneamento básico e acesso a água; } \\
\text { acesso a informações públicas e políticas } \\
\text { públicas do município. }\end{array}$ \\
\hline $\begin{array}{l}\text { A luta histórica dos indígenas xakriabás em } \\
\text { 1970 e 1980 protagonizadas por Rosalino, e } \\
\text { a demarcação da reserva indígena; ações de } \\
\text { saúde e educação diferenciadas no território } \\
\text { xakriabá. }\end{array}$ & $\begin{array}{l}\text { Dificuldade de formação de novas } \\
\text { lideranças; preocupação com o futuro da } \\
\text { juventude. }\end{array}$ \\
\hline $\begin{array}{l}\text { Suspensão da liminar de reintegração de } \\
\text { posse (junho 2016) através do estudo } \\
\text { técnico realizado pelo CAA; posto artesiano } \\
\text { da Funasa a partir do Programa água para } \\
\text { todos; criação dos vales dos quilombos com } \\
\text { o objetivo de fortalecer a articulação dos } \\
\text { quilombos da região. }\end{array}$ & $\begin{array}{l}\text { Fechamento em 2002 do Colégio Estadual } \\
\text { localizado no território do Quilombo da } \\
\text { Praia, onde quase todos estudaram; falta } \\
\text { denergia; impasse no acordo de } \\
\text { cooperação técnica entre o INCRA e a } \\
\text { Unimontes para a realização do relatório } \\
\text { antropológico do Quilombo da Praia e } \\
\text { Buriti do Meio. }\end{array}$ \\
\hline
\end{tabular}

FONTE: Dados registrados pela autora no 70 Encontro da Articulação dos Vazanteiros em Movimento, 2017.

Percebe-se que estas comunidades têm se reunido motivadas pelo compartilhamento de expressões coletivas, combinando a organização política e o reconhecimento da identidade, em um processo de apropriação de discurso para a reapropriação territorial. Dentre os avanços importantes consideram os trabalhos antropológicos feitos nos territórios e as parcerias construídas, especialmente no âmbito jurídico. As principais dificuldades são sobre o diálogo com as instâncias governamentais, a criminalização dos modos de vida e a restrição das práticas de manejo, desdobrando num processo de judicialização e burocratização das lutas.

Ao mesmo tempo, um conjunto de problemáticas centra-se na obtenção de 
Dossiê | Conflitos ambientais no Norte De Minas Gerais: o 7º Encontro da Articulação dos Vazanteiros em Movimento (SILVA, Queite Marrone Soares da; KUBO, Rumi Regina)

infraestrutura básica (saneamento, escola) para a manutenção, sustentabilidade e reprodução social das comunidades. Outra ordem de preocupações relaciona-se ao âmbito de mobilização política em que é destacado o alinhamento a outros movimentos, sob o escopo da categoria povos e comunidades tradicionais, assim como a formação de lideranças, em que há a preocupação da inserção de jovens. Neste sentido, desejam uma formação política continuada das comunidades, a organização das reivindicações, a contínua participação em projetos e políticas públicas, e o fortalecimento da rede de parcerias.

Como questão de fundo a esses debates e encontros, as lideranças retomaram críticas ao processo de Modernização Conservadora, Revolução Verde, criação do Projeto Jaíba e das Unidades de conservação, e os impactos causados aos povos vazanteiros e demais grupos sociais da região.

O encerramento do evento ocorreu com o destaque que foi dado para o contexto da alteração/restrição das formas de uso e apropriação dos recursos naturais, que intensifica a desorganização dos sistemas de manejo, produção e reprodução dos grupos sociais na (re) construção dos seus modos de vida, (re) forçando a necessidade contínua de construção de estratégias de resistências cotidianas.

\section{Considerações finais}

A racionalidade econômica capitalista ao se manifestar sobre o meio ambiente interfere nas condições de (re)produção das comunidades locais, haja visto que a degradação do meio ambiente, da biodiversidade, e dos ecossistemas provoca a modificação das práticas de manejo e gestão dos recursos naturais, forçando a reorientação de estratégias de resistência, que resultam nas constantes mobilizações e reivindicações.

Para as comunidades tradicionais estes processos interferiram nas condições de vida, nos sistemas de produção e no domínio territorial, significando um violento processo de rupturas. As mudanças nas práticas sociais, produtivas e reprodutivas refletem as conseqüências e os impactos socioambientais ocasionados a estes grupos sociais, por meio da inserção de empreendimentos econômicos que desconsideraram suas singularidades. 
Dossiê | Conflitos ambientais no Norte De Minas Gerais: o 7ํㅡㄹ Encontro da Articulação dos Vazanteiros em Movimento (SILVA, Queite Marrone Soares da; KUBO, Rumi Regina)

Deste modo, a efetivação das unidades de proteção integral provocou/provoca restrições nos modos de vida destas comunidades vazanteiras que dependem diretamente dos recursos naturais para a reprodução social. No entanto, se encontram submetidas aos processos históricos de encurralamento, expropriação territorial, e desorganização social, pela hegemonia da política de Estado em favor dos grandes projetos de desenvolvimento econômico.

Portanto, a Articulação dos Vazanteiros em Movimento significa um importante instrumento de visibilização e continuidade da luta em defesa dos seus territórios e modos de vida, reforçando o aspecto dinâmico destas lutas sociais, o que justifica a designação assumida pelo grupo de "Encurralados pelos Parques" ressignificada à "Vazanteiros em Movimento".

\section{Agradecimentos}

Agradecemos as contribuições fundamentais da Articulação dos Vazanteiros em Movimento; às experiências junto ao Núcleo Interdisciplinar de Investigação Socioambiental da Universidade Estadual de Montes Claros, por meio do Projeto "Dinâmicas socioambientais na bacia média do rio São Francisco mineiro: Identificação e caracterização de terras tradicionalmente ocupadas por povos e comunidades tradicionais", em parceria com a Rede Tropi-Dry Internacional, que possibilitaram através dos recursos financeiros referentes à bolsa de pesquisa - o registro e coleta de dados; e a Coordenação de Aperfeiçoamento de Pessoal de Nível Superior (CAPES), que no contexto atual financia a continuidade desta pesquisa.

\section{Referências}

ACSELRAD, Henri. Conflitos Ambientais no Brasil. Rio de Janeiro: Relume Dumará, 2004.

ACSELRAD, Henri. Ambientalização das lutas sociais - o caso do movimento por justiça ambiental. Estudos Avançados 24 (68), 2010.

ALMEIDA, Alfredo Wagner Berno de. Terras tradicionalmente ocupadas: processos de territorialização e movimentos sociais. Revista Brasileira de Estudos Urbanos e Regionais 6.1.2011. 
Dossiê | Conflitos ambientais no Norte De Minas Gerais: o 7ํㅡㄹ Encontro da Articulação dos Vazanteiros em Movimento (SILVA, Queite Marrone Soares da; KUBO, Rumi Regina)

ANAYA, Felisa. De "Encurralados pelos Parques" a "Vazanteiros em Movimento": As reivindicações territoriais das comunidades vazanteiras de Pau Preto, Pau de Légua e Quilombo da Lapinha no campo ambiental. Tese de doutorado, UFMG, 2012.

ANAYA, Felisa Cançado. "Vazanteiros em movimento": o processo de ambientalização de suas lutas territoriais no contexto das políticas de modernização ecológica. In: Ciência \& Saúde Coletiva [online], 2014, v.19, n. 10, pp.4041-4050.

BRANDÃO, Carlos Rodrigues. A comunidade tradicional. In: COSTA, João Batista de Almeida. LUZ, Cláudia (Orgs). Cerrado, Gerais, Sertão: comunidades tradicionais dos sertões roseanos. Montes Claros, 2000.

Brasil. Decreto № 6.040, de 7 de Fevereiro de 2007. Disponível em: http://www.planalto.gov.br/ccivil 03/ ato2007-2010/2007/decreto/d6040.htm.

Acesso em 10 de Agosto de 2018.

COSTA, João Batista de Almeida. A (DES) Invisibilidade dos Povos e Comunidades Tradicionais: A produção da Identidade, do Pertencimento e do Modo de Vida como Estratégia para efetivação de direito coletivo. In: GAWORA; SOUZA IDE; BARBOSA. Povos e Comunidades Tradicionais no Brasil. Montes Claros: Editora Unimontes, 2011.

COSTA, João Batista. A invenção dos sujeitos de direitos e processos sociais: povos e comunidades tradicionais no Brasil e no Norte de Minas Gerais. Belo Horizonte: Initia Via, 2015.

DAYRELL, C. A. Os geraizeiros descem a serra ou a agricultura de quem não aparece nos relatórios dos agrobusiness. In: DAYRELL, C. A.; OLIVEIRA, Cláudia. L. Cerrado e desenvolvimento: Tradição e atualidade. Montes Claros: UNIMONTES, 2000. p.191-274.

DIEGUES, A.C. O mito moderno da natureza intocada. São Paulo: Hucitec, 2001. FEITOSA, Antônio Maurílio A; BARBOSA, Rômulo Soares. A dinâmica de Luta pela Terra no Norte de Minas Gerais. In: FEITOSA, A. M. et al. Debaixo da Lona: Tendências e Desafios Regionais da Luta pela posse da Terra e da Reforma Agrária no Brasil. Goiânia: Editora da UCG, 2006.

FRANÇA, lara S. de; BARBOSA, Rômulo S.; SOARES, Beatriz Ribeiro. O Sertão Norte-Mineiro e suas transformações recentes. Montes Claros: Editora Iseib, 2006. v.2. n. 1.

GONÇALVES, Carlos Walter Porto. AS MINAS E OS GERAIS: Breve Ensaio sobre Desenvolvimento e Sustentabilidade a partir da Geografia do Norte de Minas. In: DAYRELL, Carlos; LUZ, Cláudia. Orgs. Cerrado e Desenvolvimento: Tradição e Atualidade. Montes Claros, 2000.

LITTLE, Paul. Territórios Sociais e Povos tradicionais no Brasil: por uma antropologia da territorialidade. In: Simpósio "Natureza e Sociedade: desafios epistemológicos e metodológicos para a antropologia". XXIII Reunião brasileira de antropologia, Gramado-RS, 19 de junho de 2002. 
OLIVEIRA, Cláudia Luz. Vazanteiros do Rio São Francisco: um estudo sobre populações tradicionais e territorialidade no Norte de Minas Gerais. Belo Horizonte: Dissertação de Mestrado. UFMG, 2005.

POSWAR, Carolina. "Unidades de Conservação e Soberania Alimentar: uma análise da Comunidade Vazanteira Ilha de Pau de Légua, no entorno do Parque Estadual da Mata Seca, Norte de Minas Gerais. Dissertação de Mestrado. Unimontes, 2011.

RIBEIRO, Ricardo Ferreira. História Ecológica do Sertão Mineiro e a Formação do Patrimônio Cultural Sertanejo. In: DAYRELL, Carlos; LUZ, Cláudia. Orgs. Cerrado e Desenvolvimento: Tradição e Atualidade. Montes Claros, 2000.

SANTOS, Kleber. Heterogeneidade nas estratégias de sustento: A experiência da Intervenção Planejada na Etapa 1 do Projeto Jaíba, Minas Gerais. Tese de doutorado. UFRGS, 2013. 